\title{
Stigmaeus solidus Kuznetsov (Acari, Raphignathoidea, Stigmaeidae)'un Türkiye ve Hollanda örnekleri üzerinden yeniden tanımı ${ }^{1}$

\author{
Redescription of Stigmaeus solidus Kuznetsov (Acari, Stigmaeidae) based on the \\ Turkish and Dutch specimens
}

\section{Salih DOĞAN ${ }^{2 *} \quad$ Sibel D LKARAOĞLU ${ }^{2,3} \quad$ Orhan ERMAN $^{3} \quad$ Farid FARAJI $^{4}$ Meryem B NGÜL ${ }^{2} \quad$ Erhan ZEYTUN $^{2} \quad$ Firdevs ERS N ${ }^{5}$}

\begin{abstract}
Summary
Redescription of Stigmaeus solidus Kuznetsov (Acari, Stigmaeidae) was given based on the specimens collected from Turkey and The Netherlands, its original figures were illustrated, and distribution in the world of the species was emphasized. Some structural variations on setae $h_{2}$ in the female were observed. Male and deutonymph of this species were included for the first time in this study. S. solidus was given before from the type locality, Russia, and reported previously from Kelkit Valley in Turkey. It is determined that this was newly recorded species for the Dutch mite fauna and for the second time from Harşit Valley with this study.
\end{abstract}

Key words: Acari, Stigmaeus, Harşit Valley, The Netherlands, Turkey

\section{Özet}

Bu çalışmada, Stigmaeus solidus Kuznetsov'un (Acari, Stigmaeidae) yeniden tanımı Türkiye ve Hollanda'dan toplanan örnekler üzerinden verilmiş, türün özgün şekilleri çizilmiş ve dünyadaki yayılışı üzerinde durulmuştur. Dişinin $h_{2}$ kıllarında yapısal varyasyonlar gözlenmiştir. Türün erkeğine ve dötonimf evresine ilk kez bu çalışmada yer verilmiştir. Bu türün ilk defa tip yeri olan Rusya'dan verildiği, Türkiye'den ise daha önce Kelkit Vadisi'nden rapor edildiği, bu çalışma ile ikinci kez Harşit Vadisi'nden kaydedildiği ve Hollanda akar faunası için yeni kayıt niteliğinde olduğu belirlenmiştir.

Anahtar sözcükler: Acari, Stigmaeus, Harşit Vadisi, Hollanda, Türkiye

\footnotetext{
${ }^{1}$ Bu çalışma, ikinci yazarın doktora tezinden bazı veriler içermektedir

2 Erzincan Üniversitesi, Fen Edebiyat Fakültesi, Biyoloji Bölümü, Erzincan, Türkiye

${ }^{3}$ Fırat Üniversitesi, Fen Fakültesi, Biyoloji Bölümü, Elazığ, Türkiye

${ }^{4}$ Mitox Consultants/ Eurofins, Amsterdam, Hollanda

${ }^{5}$ Ege Üniversitesi, Ziraat Fakültesi, Bitki Koruma Bölümü, zmir, Türkiye

* Sorumlu yazar (Corresponding author) e-mail: salihdogan@erzincan.edu.tr

Alınış (Received): 09.05.2015 Kabul ediliş (Accepted): 21.01.2016
} 


\section{Giriş}

Prostigmata alttakımında yer alan ve yumuşak vücut yapısına sahip olan raphignathoid akarlar, 56.5 milyon yıllık tarihi ile dünyanın en eski akar gruplarından birini oluşturmaktadır (Fan \& Zhang, 2005). Geniş bir dağılışa sahip olan bu grup, günümüzde 11 familya, 62 cins ve 900'ün üzerinde türle temsil edilmektedir (Fan \& Zhang, 2005; Zhang et al., 2011). Stigmaeidae, raphignathoidlerin en zengin familyasıdır. Günümüzde bu familya 32 cins ve 550 den fazla türle temsil edilmektedirler (Fan \& Zhang, 2005; Dönel \& Doğan, 2011; Doğan et al., 2014, 2015a,b). Bu familyanın pek çok üyesi serbest yaşayan avcılar olup, çeşitli eklembacaklılarla geçinirler (Fan \& Zhang, 2005). Ülkemizde şuana kadar bu familyanın 11 cinsine rastlanmıştır (Doğan et al., 2015a; Uluçay, 2015 a,b). Bunlar; Agistemus Summers, Cheylostigmaus Willmann, Eryngiopus Summers, Eustigmaeus Berlese, Ledermuelleriopsis Willmann, Mediolata Canestrini, Prostigmaeus Kuznetsov, Stigmaeus Koch, Storchia Oudemans, Villersia Oudemans ve Zetzellia Oudemans'dır. Bunlardan tür çeşitliliği bakımından en zengin olanı Stigmaeus'dur. Şimdiye kadar bu cinsin dünyada 144, ülkemizde ise 29 türü tanımlanmıştır (Yeşilayer \& Çobanoğlu, 2013; Doğan et al., 2015a; Uluçay, 2015 a,b; Khanjani et al., 2015; Fakhari et al., 2015).

Stigmaeid akarlar dünyanın birçok yerinde geniş dağılıma sahip olmasına rağmen, dünyada ve ülkemizde yapılan çalışmalar mevcut faunayı ortaya koymaktan uzaktır. Bu çalışma ile Türkiye ve dünya akar faunasına katkıda bulunmak amaçlanmıştır. Çalışma kapsamında Harşit Vadisi'nden 53 dişi, 1 erkek, 2 dötonimf, Hollanda'dan ise 1 dişi Stigmaeus solidus örneğine rastlanmıştır. Bu çalışma ile Stigmaues solidus'un Türkiye örnekleri ile Hollanda örneği yapısal olarak kıyaslanmış ve suranal kıllardan $h_{2}$ 'de varyasyon olduğu tespit edilmiştir. Türün suranal kıllarının yapısal olarak varyasyon göstermesi, erkek bireye ve dötonimf evresine ilk kez rastlanılmış olması ve türün Hollanda için yeni kayıt niteliğinde olması, türün yeniden tanımlanmasını gerekli kılmıştır.

\section{Materyal ve Yöntem}

Çalışma kapsamında Harşit Vadisi ve Hollanda'dan toplanan akarlar içerisinden Stigmaeus cinsine ait örnekler incelenmiştir. Çalışma alanlarından alınan toprak, döküntü, ağaç kabuğu ve yosun örnekleri naylon torbalara konularak etiketlenip laboratuvara getirilerek birleştirilmiş Berlese hunilerinden oluşan ayıklama düzeneğine yerleştirilmiştir. Düzenek yardımıyla içinde $\% 70$ 'lik etil alkol içeren toplama şişelerine biriktirilen akarlar Petri kaplarına boşaltıldıktan sonra stereo mikroskop altında ayıklanmıştır. \%60'lık laktik asit kullanılarak ağartılan akar örneklerinin Hoyer eriyiğinde daimi preparatları yapılmış ve mikroskobik incelemeleri gerçekleştirilmiştir. Akarların genel görünüşü ve ayırt edici karakterlerine ait çizimleri uygun büyütme ve açılardan Leica DM 4000 model faz-kontrast donanımlı ışık mikroskobu kullanılarak yapılmıştır. Vücut büyüklüğü ve çeşitli vücut yapılarının ölçümleri ise LAS V 3,8 programı yardımıyla $\mu \mathrm{m}$ cinsinden alınmıştır. Vücut uzunluk ölçümüne gnatozoma dahil edilmemiştir. Vücut genişliği idiozomanın en geniş kısmından yapılmıştır. Palp ve bacak uzunluklarının ölçümü ise trokanterden tarsusa kadar olan kısmı içermektedir. Metinde geçen ölçümlerde ilk verilen değer ortalamayı, parantez içerisinde verilen değerler ise değişim aralığını ifade etmektedir. Bu çalışmada değerlendirilen akarların vücut bölgeleri ile vücut ve bacak kıllarının isimlendirilmesinde Grandjean (1944) ve Kethley (1990) tarafından önerilen sistem kullanılmıştır.

\section{Araştırma Sonuçları ve Tartışma}

\section{Familya: Stigmaeidae Oudemans, 1931}

\section{Cins: Stigmaeus Koch, 1836}

Tip türü: Stigmaeus cruentus Koch, 1836

Subkapitulum iki çift kıllı $(m, n)$; keliserler ayrı; palp trokanterinden palp tarsusuna doğru kıl dağılımı: 0, 3, 1-2, 2+1tırnak+1yardımcı tırnak, 4+1solenidiyum+1subterminal öpathidiyum+1kaidede 
kaynaşmış iki ya da üç çatallı terminal öpathidiyum şeklinde, palp tibiya tırnağı palp tarsusu ile hemen hemen eşit uzunlukta ya da çok az kısa, palp tibiyasındaki yardımcı tırnak kıl ya da diken şeklinde; idiozoma oval; göz ve göz ardı cisim var ya da yok; propodozoma plağı üç çift kıl (vi, ve, scı) taşımakta, sce kılları küçük plaklar üzerinde yer almakta; dorsal histerozoma 1 ya da 2 plaklı ve bu plaklar 3-5 çift daha küçük plaklarla kuşatılmış durumda; $d_{1}$ ile $d_{2}$ kılları aynı plak üzerinde yer almaz; humeral plaklar $c_{2}$ kıllarını taşır; interkalar plaklar tam ya da bölünmüş ve $f_{1}$ kılları bu plaklar üzerinden çıkar; suranal plak tam ya da bölünmüş, 2 veya 3 çift kıl ( $h_{3}$ var veya yok) taşır; koksisternal plaklar bölünmüş; ventral opistozomada 3-5 çift aggenital kıl (ag) bulunur; genital ile anal plak kaynaşmış ya da birleşmiş, 1-3 çift genital ( $g$ ), 3 çift pseudanal kıl (ps) taşımaktadır (Fan \& Zhang, 2005; Doğan et al., 2015a).

\section{Stigmaeus solidus Kuznetsov, 1977}

Dişi $(n=5)($ Şekil 1-7, 22-24)

Vücut uzunluğu 407 (391-423), genişliği 280 (267-295)'dir.

Gnatozoma, keliser ve palp uzunlukları sırasıyla şöyledir; 80 (79-81), 104 (100-106), 120 (116125). Palp 5 parçalıdır. Palp tarsusu 4 basit kıl,1 solenidiyum ( $\omega), 1$ kıl benzeri subterminal öpathidiyum $(\mathrm{acm})$ ve 1 tane kaidede kaynaşmış uçta üç çatallı terminal öpathidiyum taşımaktadır. Palp tibiyası 2 kıl, 1 tırnak ve 1 diken şeklinde yardımcı tırnak taşımaktadır. Palp genusu 2, palp femuru 3 kıllıdır. Palp trokanteri ise kıl taşımamaktadır (Şekil 7). Subkapitulum kıllarının uzunlukları ve aralarındaki mesafeler şöyledir; m: 18 (17-20), n: 17 (16-20), m-m: 28 (27-29), n-n: 23 (22-24), m-n: 9 (8-9).

ntegüment plaklar arasında çizgilidir. Sırt plakları çukurluklu, bal peteği şeklinde desene sahiptir. Propodozoma plağı üzerinde vi, ve, sci kılları bulunmaktadır. Göz yok, göz ardı cisimler vardır. sce kılları küçük yardımcı plaklar üzerindedir. Merkezi plak üzerinde $c_{1}, d_{1}$ ve $e_{1}$ kılları, yanal plaklar üzerinde $d_{2}$ kılları, yan zonal plaklar üzerinde $e_{2}$ kılları, çift haldeki interkalar plaklar üzerinde $f_{1}$ kılları yer almaktadır. Suranal plak bütün halde ve $h_{1}$ ile $h_{2}$ kıllarını taşımaktadır. Humeral plaklar vücudun alt yanlarında olup, üzerinde $c_{2}$ kıllarını taşımaktadır. Sırt kıllarından vi, $s c i, h_{1}$ ve $h_{2}$ uçta dallı bir yapıda, diğer kıllar ise düz ve kamçı şeklinde bir görünüme sahiptir. Sırt kıllarının uzunlukları ve aralarındaki mesafeler şöyledir; vi: 53 (50-55), ve: 100 (97-106), sci: 31 (30-33), sce: 89 (85-96), c $c_{1}: 85$ (81-88), c $c_{2}: 92$ (81-100), d $: 94$ (91-97), $d_{2}: 90$ (88-92), $e_{1}: 105$ (102-107), e $2: 96$ (91-100), $f_{1}: 114$ (111-117), $h_{1}: 45$ (44-47), $h_{2}: 49$ (48-50), vi-vi: 15 (14-15), ve-ve: 87 (81-91), vi-ve: 53 (51-56), sci-sci: 149 (144-156), ve-sci: 53 (49-55), sce-sce: 187 (182-195), sci-sce: 22 (19-24), $c_{1}-c_{1}: 83$ (79-87), $d_{2}-d_{2}: 235$ (230-243), $c_{1}-d_{1}: 74$ (73-75), $c_{1}-d_{2}: 95$ (89$100), d_{1}-d_{1}: 89$ (84-93), $d_{2}-d_{1}: 73$ (70-75), $e_{2}-e_{2}: 201$ (198-204), $d_{2}-e_{2}: 71$ (68-74), $d_{1}-e_{1}: 65$ (64-66), $d_{1}-e_{2}:$ 80 (77-82), $e_{1}-e_{1}: 66$ (65-68), $e_{2}-e_{1}: 64$ (62-66), $f_{1}-f_{1}: 118$ (115-123), $e_{1}-f_{1}: 48$ (45-54), $e_{2}-f_{1}: 67$ (66-69), $f_{1}-$ $h_{1}: 51$ (46-56), $f_{1}-h_{2}: 29$ (25-35), $h_{1}-h_{1}: 50$ (49-52), $h_{2}-h_{2}: 98$ (96-100), $h_{1}-h_{2}: 27$ (20-32). ve/sci oranı 3,2 $(3,2)$.

Koksisternal plaklar bölünmüş, ağsı desenli ve üzerinde 1a, 3a ve 4a kıllarını taşımaktadır. Bu kılların uzunlukları ve aralarındaki mesafeler şöyledir; $1 a: 18$ (17-18), 3a: 17 (16-17), $4 a$ : 16 (15-17), 1a1a: 24 (23-25), 3a-3a: 25 (25-26), 4a-4a: 20 (19-21). Aggenital plak ağsı desenli ve üç çift kıl taşımaktadır. Anal ve genital plaklar kaynaşmış olup, bir çift genital $\left(g_{1}\right)$ ve üç çift pseudanal $\left(p s_{1-3}\right)$ kıl taşır. $p s_{1}$, diğer pseudanal kıllardan daha uzundur ve sırt kıllarından vi, sci, $h_{1}$ ve $h_{2}$ 'de olduğu gibi uçta dallanmış yapıdadır. Bu kılların uzunlukları şöyledir; $a g_{1}$ : 18 (17-19), $a g_{2}$ : 18 (17-18), $a g_{3}: 21$ (20-21), $g_{1}$ : 12 (12-13), ps : 32 (30-33), $p s_{2}: 23$ (22-23), $p s_{3}: 18$ (17-18).

Bacak koksalarında desen ayırt edilebilmektedir. Bacak uzunlukları sırasıyla; I.B: 196 (185-206), II.B: 165 (154-177), III.B: 159 (145-171), IV.B: 182 (169-192). Bacak parçaları üzerindeki kılların dağılımı ise şöyledir (I-IV); koksa: 2-2-2-2, trokanter: 1-1-2-1, femur: 6-5-3-2, genu: 3(+1k)-3(+1k)-1-1, tibiya: $5(+1 \varphi \rho+1 \varphi)-5(+1 \varphi \rho)-5(+1 \varphi \rho)-5(+1 \varphi \rho)$, tarsus: $13(+1 \omega)-9(+1 \omega)-7(+1 \omega)-7(+1 \omega)$. Tüm tarsuslarda $\omega$ solenidiyumu vardır. 


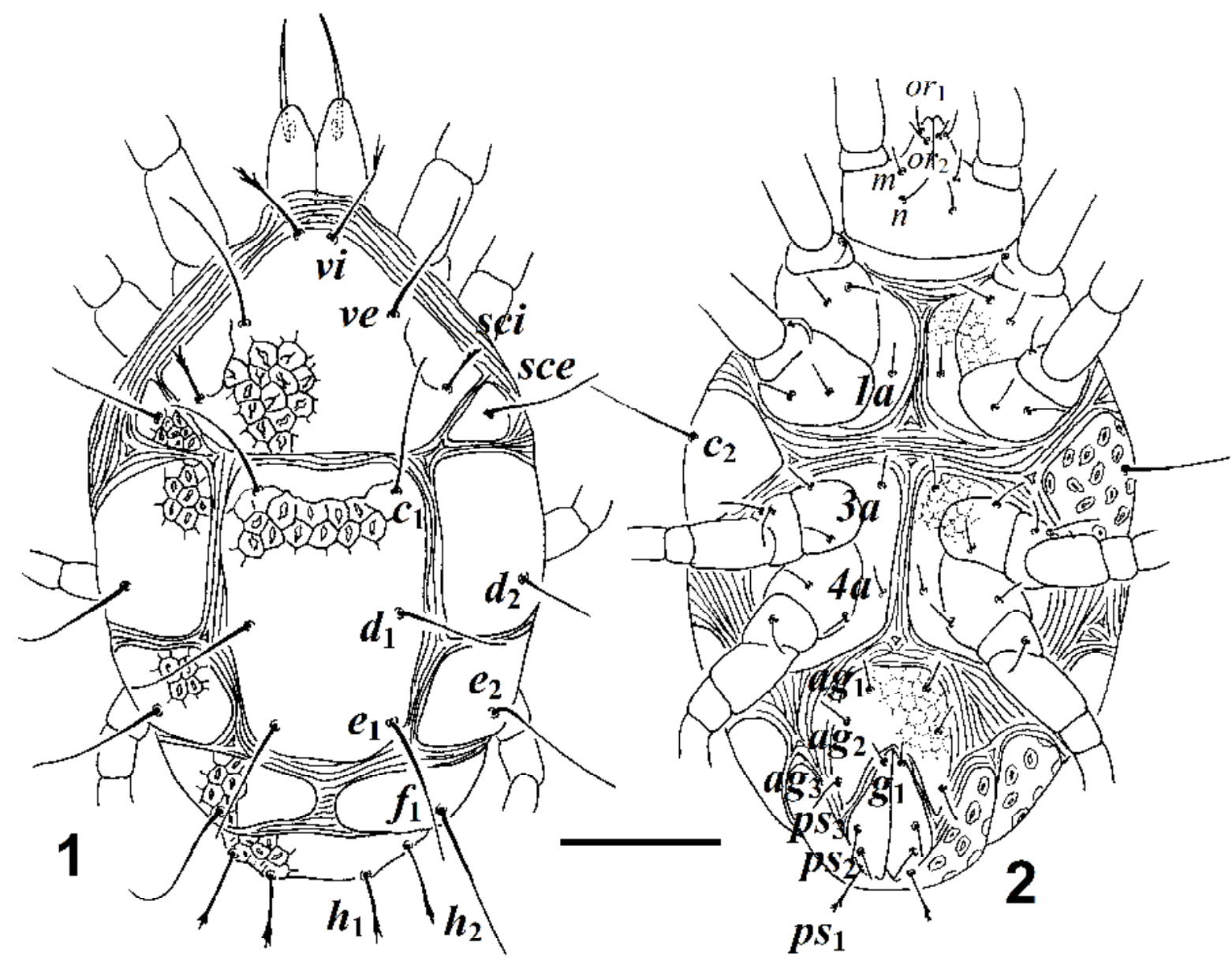

Şekil 1, 2. Stigmaeus solidus (Dişi).1. Vücut sırttan, 2. Vücut karından; ölçek $100 \mathrm{~m}$.

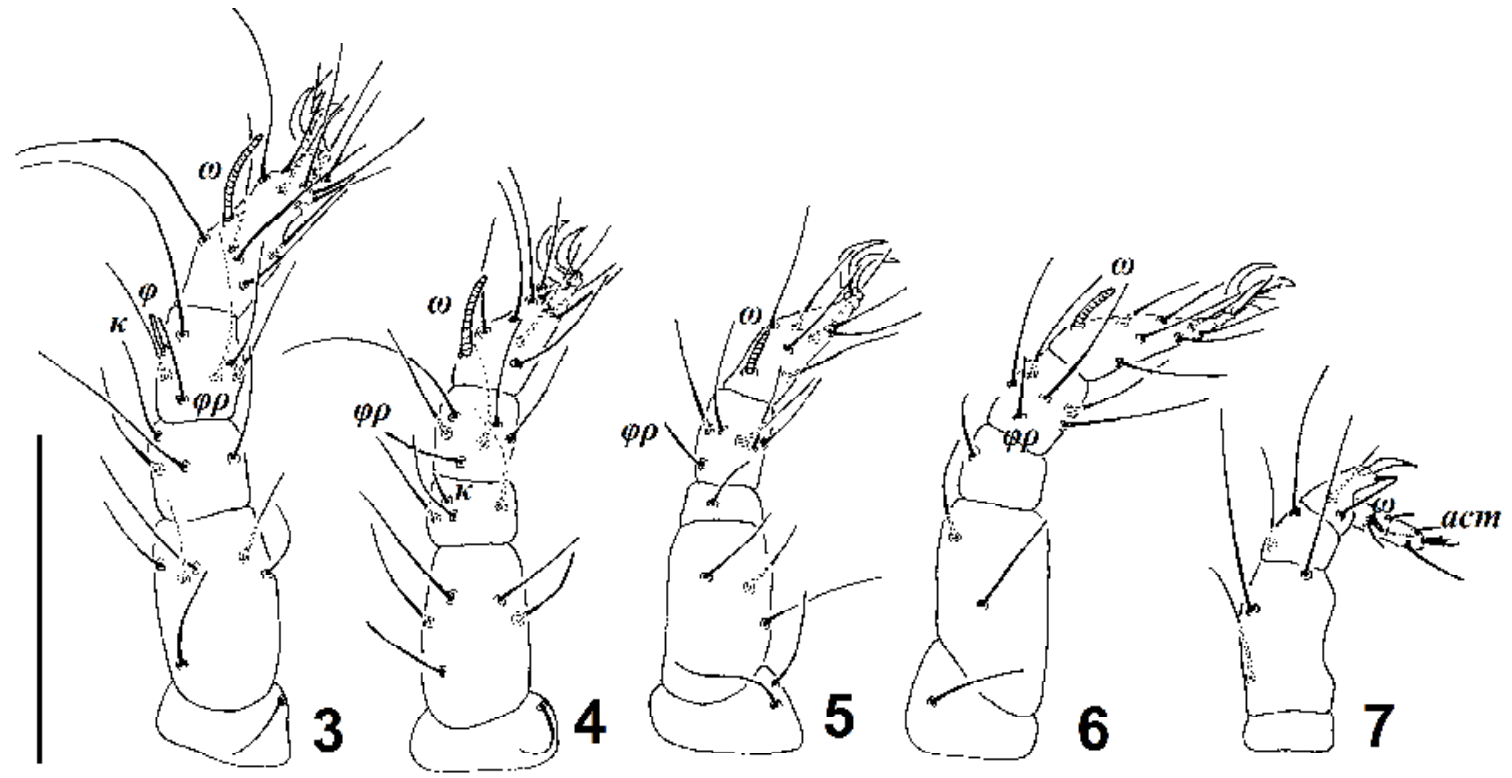

Şekil 3-7. Stigmaeus solidus (Dişi). 3. I. bacak, 4. II. bacak, 5. III. bacak, 6. IV. bacak, 7. Palp; ölçek $100 \mathrm{~m}$. 
Erkek $(\mathrm{n}=1)$ (Şekil 8-14)

Vücut uzunluğu 288, genişliği 175 'tir.

Gnatozoma, keliser ve palp uzunlukları sırasıyla; 66, 91, 88. Subkapitulum kıllarının uzunlukları ve aralarındaki mesafeler şöyledir; m: 10, $n: 12, m-m: 25, n-n: 21, m-n: 9$. Palp parçaları üzerindeki kılların dağııımı dişi ile aynıdır.

ntegüment plaklar arasında çizgilidir. Sırt plaklarındaki desen dişi bireylerde olduğu gibidir. Propodozoma plağı üzerinde vi, ve, sci ile sce kılları bulunmaktadır. Göz yok, göz ardı cisimler vardır. Merkezi plak üzerinde $c_{1}, d_{1}, e_{1}$ ile $d_{2}$ kılları bulunmaktadır. Dişiden farklı olarak yardımcı plaklar propodozoma plağıyla, yanal plaklar ise merkezi plakla kaynaşmış durumdadır. Yan zonal plaklar üzerinde $e_{2}$ kılları, çift haldeki interkalar plaklar üzerinde $f_{1}$ kılları yer almaktadır. Suranal plak bütün halde ve $h_{1}$ ile $h_{2}$ kıllarını taşımaktadır. Humeral plaklar üzerinde vücudun alt yanlarında olup $c_{2}$ kıllarını taşımaktadır. Sırt kıllarından vi, sci, dişi bireylerde olduğu gibi uçta dallı bir yapıda, $h_{1}$ hariç diğerleri kamçı şeklindendir. $h_{1}$ kılları kısa ve küt uçludur. Sırt kıllarının uzunlukları ve aralarındaki mesafeler şöyledir; vi: 41, ve: 73, sci: 23, sce: 70, $c_{1}: 73, c_{2}: 54, d_{1}: 75, d_{2}: 72, e_{1}: 73, e_{2}: 75, f_{1}: 78, h_{1}: 13, h_{2}: 31$, vi-vi: 16, ve-ve: 62, vi-ve: 38, sci-sci: 108, ve-sci: 44, sce-sce: 146, sci-sce: 14, $c_{1}-c_{1}: 56, d_{2}-d_{2}: 156, c_{1}-d_{1}: 58, c_{1}-d_{2}: 61$, $d_{1}-d_{1}: 58, d_{2}-d_{1}: 49, e_{2}-e_{2}: 132, d_{2}-e_{2}: 49, d_{1}-e_{1}: 45, d_{1}-e_{2}: 45, e_{1}-e_{1}: 43, e_{2}-e_{1}: 46, f_{1}-f_{1}: 75, e_{1}-f_{1}: 31, e_{2}-f_{1}:$ $45, f_{1}-h_{1}: 30, f_{1}-h_{2}: 18, h_{1}-h_{1}: 22, h_{2}-h_{2}: 54, h_{1}-h_{2}: 13$.

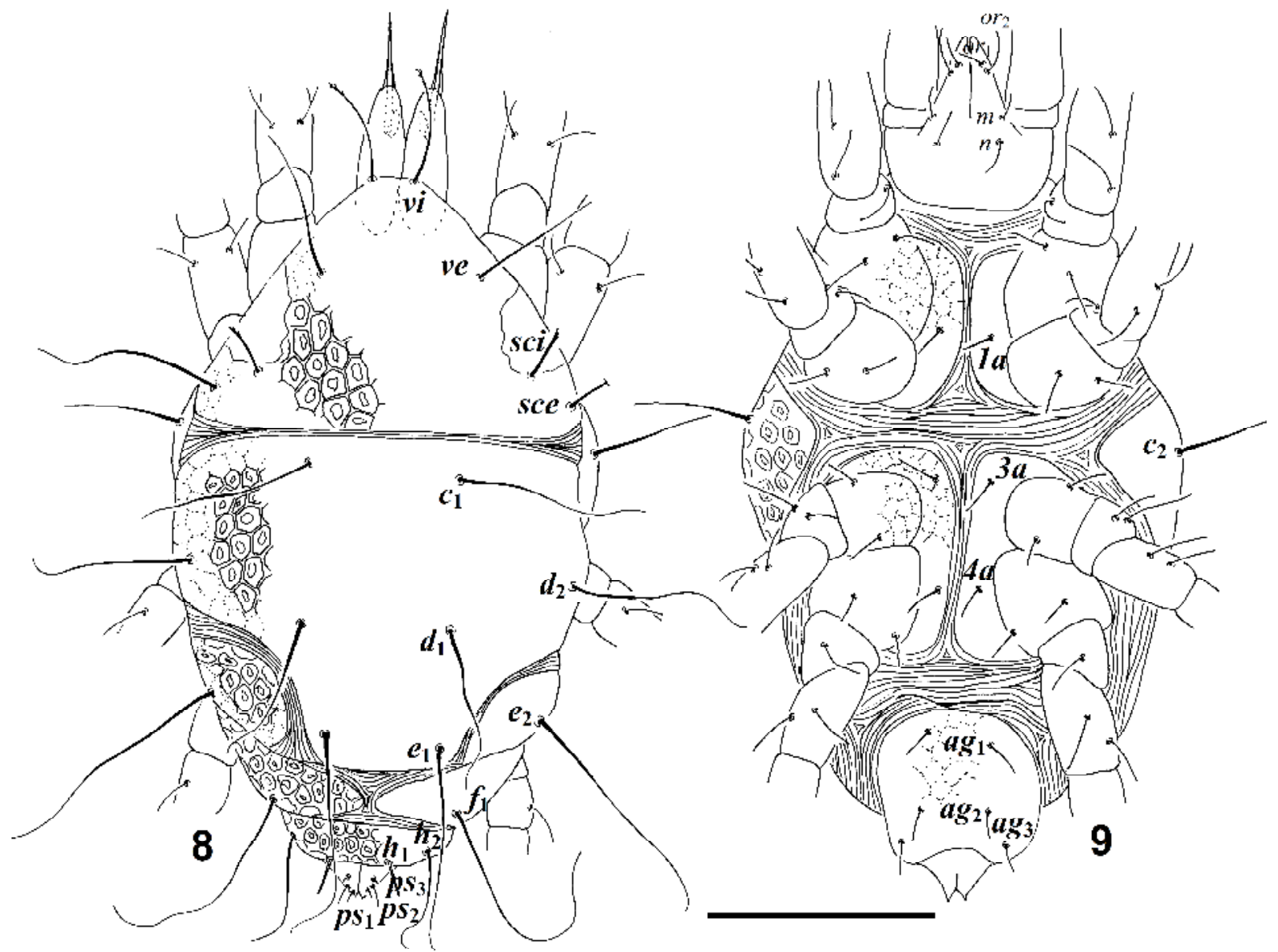

Şekil 8, 9. Stigmaeus solidus (Erkek).8. Vücut sırttan, 9. Vücut karından; ölçek 100 m. 
Koksisternal plaklar bölünmüş yapıda, ağsı desenli ve üzerinde $1 a$, 3a ve $4 a$ kıllarını taşımaktadır. Bu kılların uzunlukları ve aralarındaki mesafeler şöyledir; 1a: 13, 3a: 15, 4a: 12 1a-1a: 20, 3a-3a: 21, 4a4a: 13. Aggenital plak ağsı desenli ve üç çift kıllıdır. Anal plak vücudun arka ucunda ve üç çift pseudanal $\left(p s_{1-3}\right)$ kıl taşır. Bu kılların uzunlukları şöyledir; $a g_{1}: 12, a g_{2}: 12, a g_{3}: 14, p s_{1}: 8, p s_{2}: 4, p s_{3}: 3$.

Bacak koksalarında desen ayırt edilebilmektedir. Bacak uzunlukları sırasıyla; I.B: 177, II.B: 150, III.B: 129, IV.B: 154. Bacak parçaları üzerindeki kılların dağılımı ise şöyledir (I-IV); koksa: 2-2-2-2, trokanter: $1-1-2-1$, femur: $6-5-3-2$, genu: $3(+1 \kappa)-3(+1 \kappa)-1-1$, tibiya: $5(+1 \varphi \rho+1 \varphi)-5(+1 \varphi \rho)-5(+1 \varphi \rho)-$ $5(+1 \varphi \rho)$, tarsus: $13(+2 \omega)-9(+2 \omega)-7(+2 \omega)-7(+2 \omega)$.
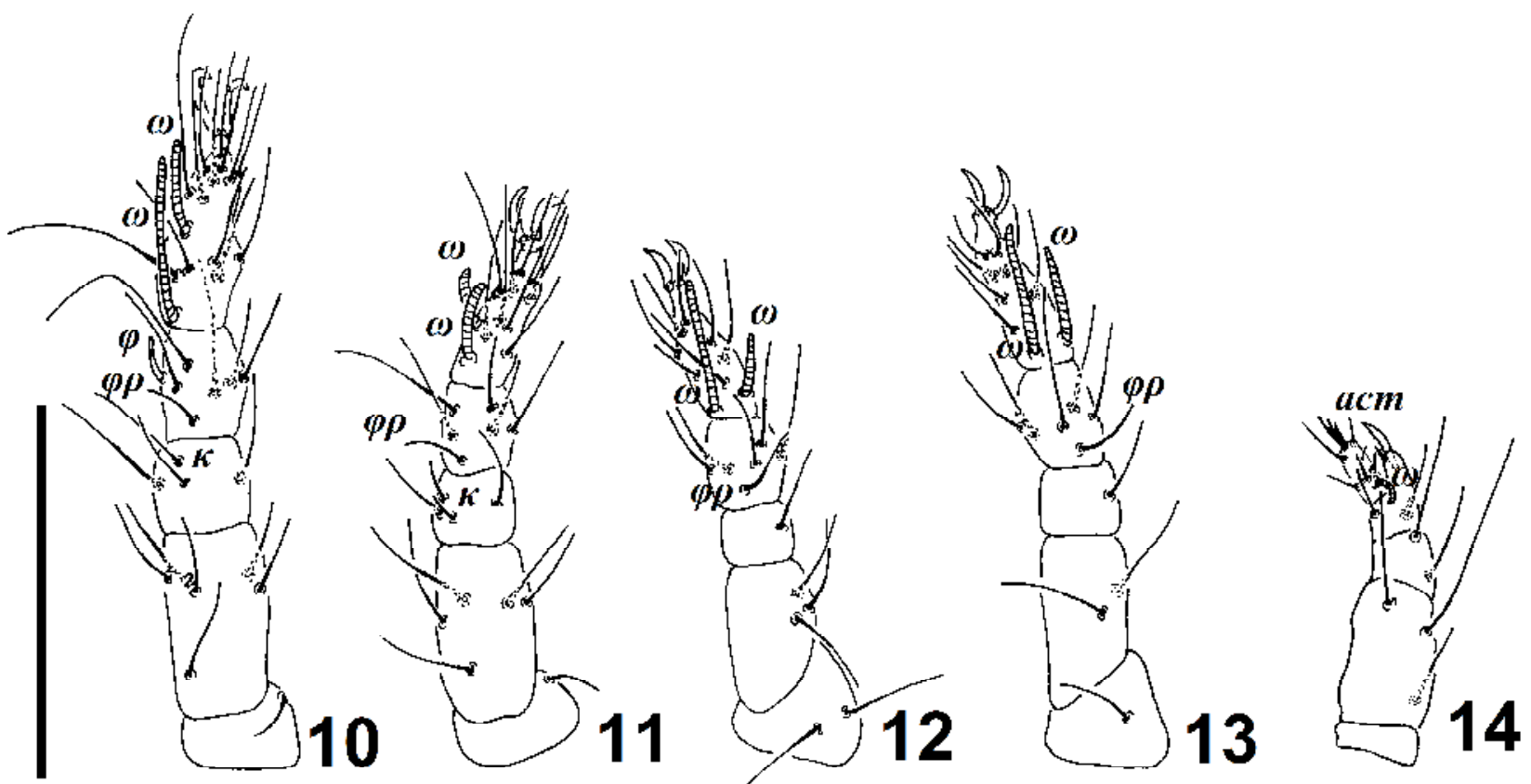

Şekil 10-14. Stigmaeus solidus (Erkek). 10. I. bacak, 11. II. bacak, 12. III. bacak, 13. IV. bacak, 14. Palp; ölçek 100 m.

\section{Dötonimf $(n=2)$ (Şekil 15-21)}

Vücut uzunluğu 296 (292-300), genişliği 184 (174-193).

Gnatozoma 64 (63-65), keliser 90 (90-90), palp 90 (88-91). Subkapitulum kıllarının uzunlukları ve aralarındaki mesafeler şöyledir; $m: 18$ (17-18), n: 14 (13-14), m-m: 24 (23-24), n-n: 21 (20-21), m-n: 9 (99). Palp parçaları üzerindeki kılların dağılımı dişi ile aynıdır.

Sırt deseni, plaklanma durumu ve kıl yapıları dişi bireyde olduğu gibidir. Sırt kıllarının uzunlukları ve aralarındaki mesafeler şöyledir; vi: 52 (51-53), ve: 76 (75-77), sci: 25 (25-25), sce: 73 (72-73), c 1 : 75 (7475), $c_{2}: 57$ (56-57), $d_{1}: 74$ (73-75), $d_{2}: 78$ (77-78), $e_{1}: 75$ (74-75), e $e_{2}: 80$ (79-80), $f_{1}: 66$ (65-66), $h_{1}: 52$ (5053), $h_{2}: 30$ (28-32), vi-vi: 20 (19-21), ve-ve: 76 (75-76), vi-ve: 41 (39-42), sci-sci: 130 (129-131), ve-sci: 46 (44-47), sce-sce: 159 (155-163), sci-sce: 17 (15-18), $c_{1}-c_{1}: 72$ (71-72), $d_{2}-d_{2}: 180$ (179-181), $c_{1}-d_{1}: 66$ (65$67), c_{1}-d_{2}: 71$ (70-71), $d_{1}-d_{1}: 76$ (75-76), $d_{2}-d_{1}: 55$ (54-56), $e_{2}-e_{2}: 149$ (148-149), $d_{2}-e_{2}: 58$ (56-59), $d_{1}-e_{1}$ : 52 (50-53), $d_{1}-e_{2}: 55$ (54-55), $e_{1}-e_{1}: 56$ (55-57), $e_{2}-e_{1}: 51$ (49-52), $f_{1}-f_{1}: 91$ (90-91), e $e_{1}-f_{1}: 34$ (33-35), e $e_{2}-f_{1}$ : 47 (46-48), $f_{1}-h_{1}: 42$ (41-42), $f_{1}-h_{2}: 18$ (17-18), $h_{1}-h_{1}: 23$ (21-24), $h_{2}-h_{2}: 67$ (65-68), $h_{1}-h_{2}: 19$ (18-20). 
Ventralde bulunan koksisternal plaklar, aggenital ve anogenital plaklar ile taşıdıkları kıl sayıları ve yapıları dişi ile benzerlik gösterir. Ancak pseudanal $\left(p s_{1-3}\right)$ kıllardan ilk çifti diğerleri gibi düz yapılıdır. Bu kılların uzunlukları ve aralarındaki mesafeler şöyledir; 1a: 15 (14-15), $3 a: 15$ (14-15), $4 a$ : 12 (11-12), 1a1a: 22 (21-22), 3a-3a: 25 (24-25), 4a-4a: 20 (19-21), agi : 14 (13-14), aga: 14 (14-14), ag $: 14$ (13-14), $p s_{1}$ : 19 (18-20), $p s_{2}: 12(11-12), p s_{3}: 11(10-11)$.

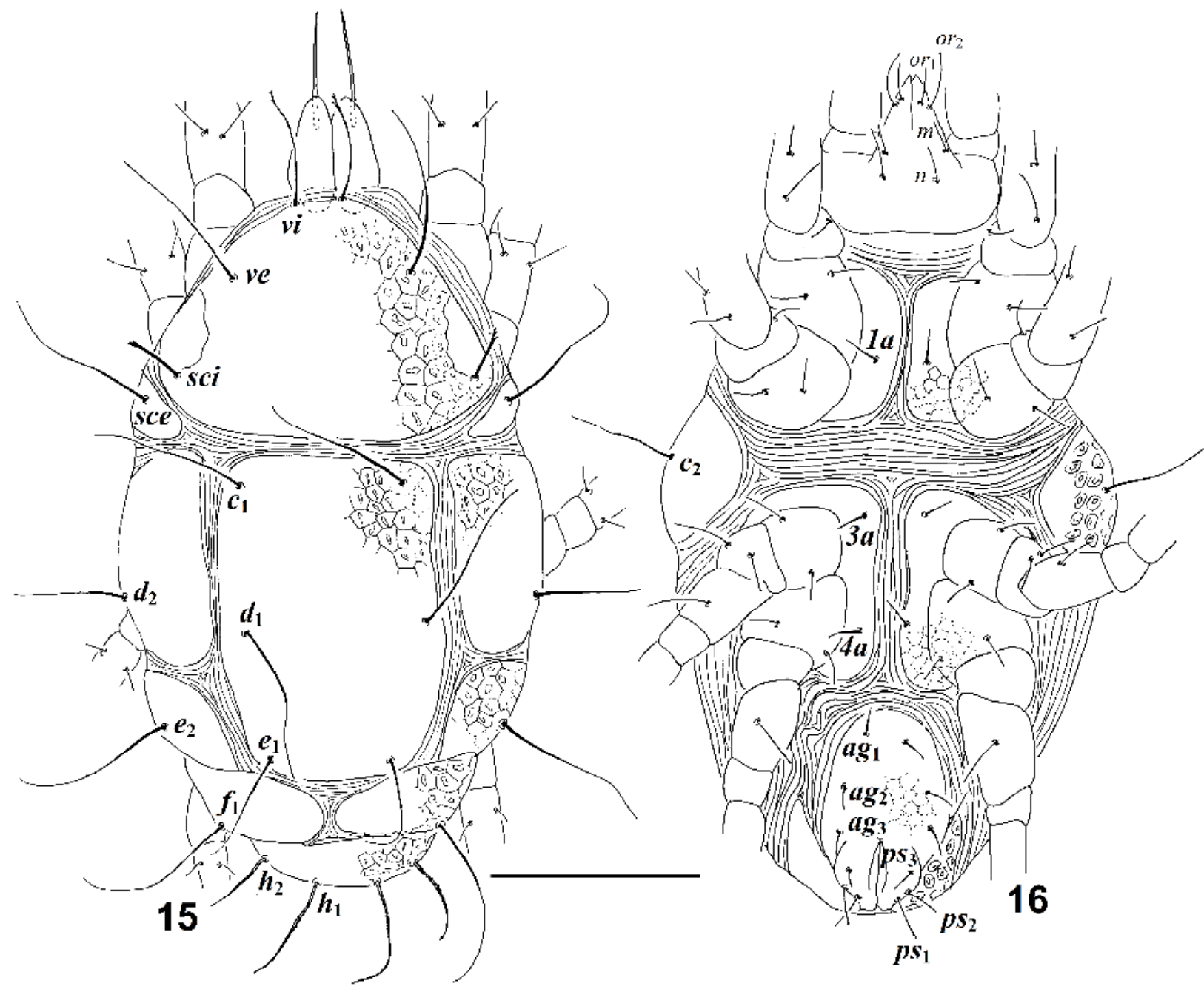

Şekil 15, 16. Stigmaeus solidus (Dötonimf).15. Vücut sırttan, 16. Vücut karından; ölçek 100 m.

Bacak koksalarında desen ayırt edilebilmektedir. Bacak uzunlukları sırasıyla; I.B: 162 (156-167), II.B: 140 (137-143), III.B: 137 (134-140), IV.B: 145 (142-147). Bacak parçaları üzerindeki kılların dağılımı ise şöyledir (I-IV); koksa: 2-2-2-2, trokanter: 1-1-2-0, femur: 6-4-3-2, genu: 3(+1k)-2(+1k)-0-0, tibiya: $5(+1 \varphi \rho+1 \varphi)-5(+1 \varphi \rho)-5(+1 \varphi \rho)-5(+1 \varphi \rho)$, tarsus: $13(+1 \omega)-9(+1 \omega)-7(+1 \omega)-7(+1 \omega)$. Tüm tarsuslarda $\omega$ solenidiyumu vardır. 


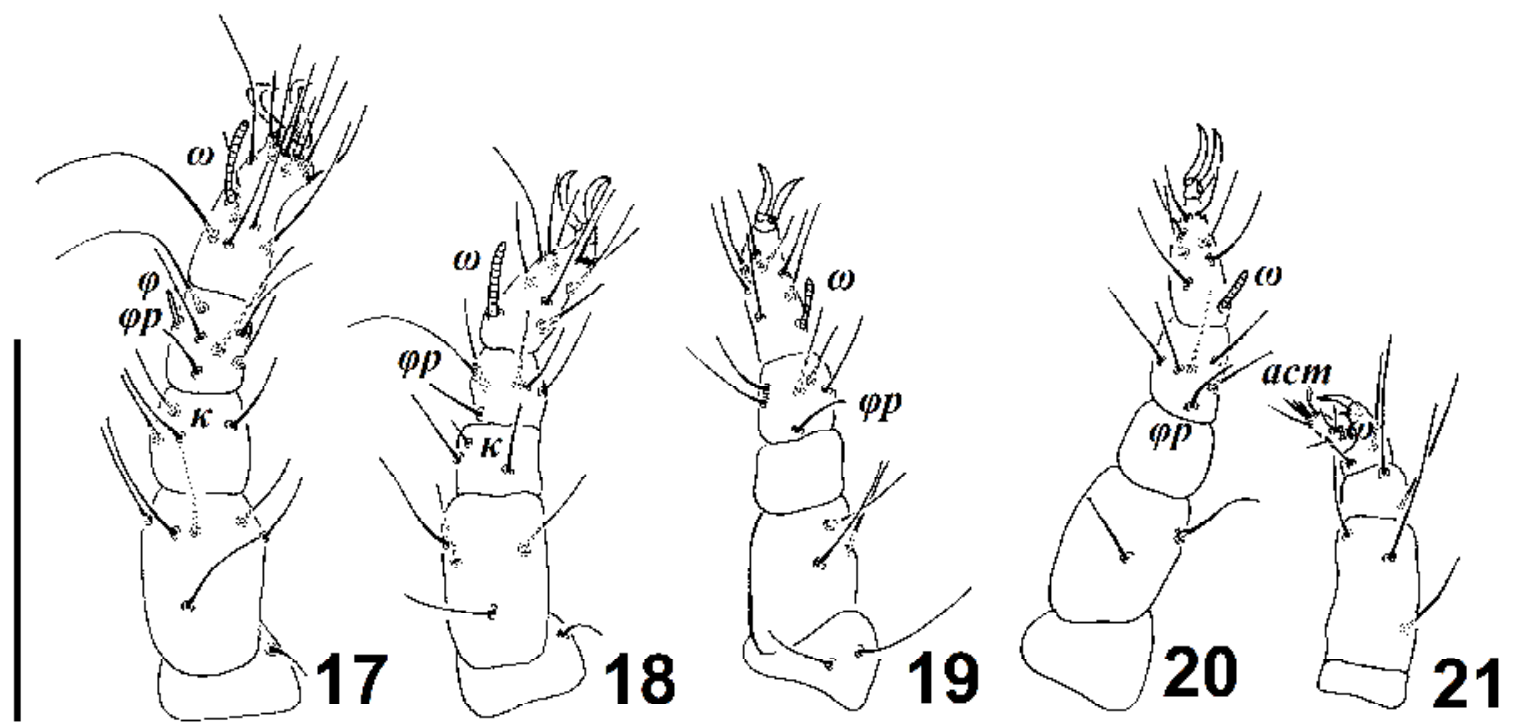

Şekil 17-21. Stigmaeus solidus (Dötonimf). 17. I. bacak, 18. II. bacak, 19. III. bacak, 20. IV. bacak, 21. Palp; ölçek $100 \mathrm{~m}$.
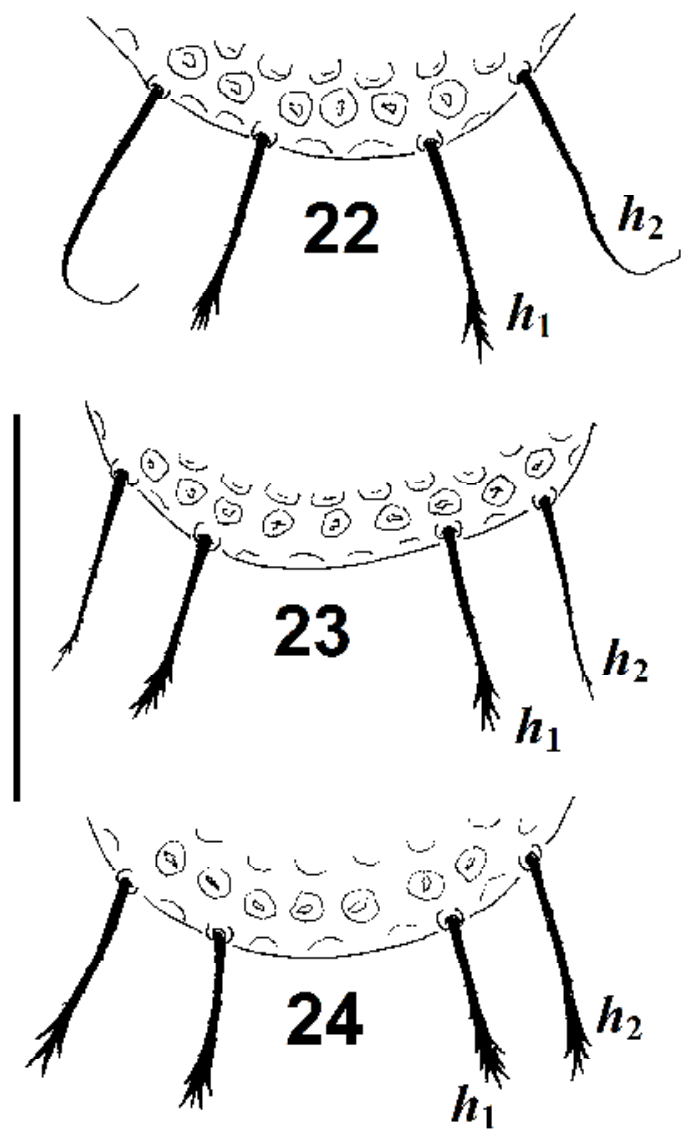

Şekil 22-24. Stigmaeus solidus (Dişi). $h_{2}$ kılındaki varyasyonlar. 22. Hollanda örneği, 23, 24. Harşit Vadisi'nden alınan örnekler; ölçek $100 \mathrm{~m}$. 
Diğer yaşam evreleri: Türün erkeğine ve dötonimf evresine dünyada ilk kez bu çalışmada değinilmiş olup, diğer yaşam evreleri henüz bilinmemektedir.

Yayılışı: Hollanda (bu eserle), Rusya (Kuznetsov, 1977) ve Türkiye ( stanbul ve Kelkit Vadisi) (Dönel \& Doğan, 2011; Yeşilayer \& Çobanoğlu, 2013).

ncelenen Örnekler: Amsterdam, Flevopark, 52 21' 30.5”K, 4 56' 51.5”D, 23.IX.2014, 1 오, yosunlu ağaç kabuğu; Çatalağaç Köyü, Seyran tepe, 1070 m, 40 46' 38'K, 38 59' 55”D, 17.IV.2014, 1우, ormangülü (Rhododendron sp.) altından döküntü; Gümüşhane yol üzeri, $1283 \mathrm{~m}, 39^{\circ} 48^{\prime} 26^{\prime \prime} \mathrm{K}, 39^{\circ} 22^{\prime}$ 50'D, 25.IX.2014, 1ㅇ, 1 Dötonimf, kavak (Populus sp.) altından döküntü; Vauk geçidi, $1800 \mathrm{~m}, 40^{\circ} 22^{\prime}$ 17'K, 39 49' 00"D, 11.IV.2014, 1 우, kızılcık (Cornus sp.) altından döküntü; Vauk geçidi, 1800 m, 40²2' 31'K, 39॰ 48' 97'D, 30.V.2014, 5 우 ㅇ, kurumuş suyolu döküntülü birikinti; Vauk geçidi, 1572 m, 40²3' 02'K, 3946' 45”D, 25.XI.2014, 45우 , 1 ơ, 1 Dötonimf, kavak (Populus sp.) altından döküntü.

\section{Tartışma}

Stigmaeus solidus, merkezi plakta üç çift kıl olması, plakların bal peteği şeklinde desene sahip olması, gözün yokluğu, göz ardı cismin varlığı ve sırt kıllarının yapısı bakımından cinsin diğer türlerinden ayrılır. Tür, bu karakterleri bakımından S. glypticus Summers benzemektedir (Summers, 1962). S. glypticus'da ve/sci 3,2 ve merkezi plak üzerindeki kıl uzunlukları $e_{1}<c_{1}<d_{1}$ şeklinde ve sırt kıllarının tümü çentikli yapıda olduğu belirtilmiştir (Summers, 1962). Bu tür ve/scinnin 2,6 ve $c_{1}, d_{1}, e_{1}$ kıllarının yaklaşık eşit uzunlukta olması ve tüm sırt kıllarının benzer yapıda olmayıp çentikli kılların dışında, kamçı şeklinde uzanan kılların da bulunması bakımından S. glypticus'dan ayrılmaktadır (Kuznetsov, 1977).

Rusya'dan verilen bu türün tip örneğinde vücut büyüklüğü 350/265, ve/sci oranı 2,6, dorsal ve ventral tüm plakların 5 veya 6 köşeli, dar sınırlarla ayrılan çukurluklu hücrelerden oluşan desene sahip olduğu, vinnin uzunluğu boyunca, scinnin ise uca doğru çentikli yapıda olduğu, diğer kılların ise uca doğru incelen yapıda, zayıf çentikli ve kamçı şeklinde olduğu belirtilmiştir (Kuznetsov, 1977).

Türkiye'den daha önce verilen örneklerde vücut büyüklüğü 375 (350-400)/248 (208-275), vi, sci, $h_{1}$ kıl uçlarının çentikli, $h_{2}$ kıllarının ise uçta zayıf çentikli, diğer kılların uzun kamçı şeklinde, koksisternal ve aggenital plakların ağsı desenli, ve/sci oranının ise 2,7 olduğu belirtilmiştir (Dönel \& Doğan, 2011).

Hollanda örneğinin vücut büyüklüğü 396/238, ve/sci oranı ise olarak 2,7 belirlenmiştir. Kıllar vi, sci, $h_{1}$ kıl uçları çentikli, $h_{2}$ kıllarının ise uçta incelen ve kamçı şeklinde devam eden bir yapıda olduğu görünmektedir. Büyüklük bakımından Türkiye örnekleri ve tip örneğinin değişim aralığı içinde olduğu söylenebilir. Ancak $h_{2}$ kılları (Şekil 22) yapısal olarak Türkiye ve tip örneğinden farklılık göstermektedir.

Türkiye'den ikinci defa bu çalışmada kaydedilen örneklerde vücut büyüklüğü 400 (391-409)/275 (269-281) olup, vi, sci, $h_{1}$ kıllarının yanında $h_{2}$ kıllarının (Şekil 23,24 ) da uçta çentikli yapıda olduğu, aggenital ve koksisternal plaklarda desen olduğu ama net olarak ayırt edilemediği söylenebilir. Harşit Vadisi'nden toplanan örneklerin hem tip örneğinden hem Türkiye'den daha önce verilen örneklerden hem de Hollanda örneğinden biraz daha büyük yapılı olduğu anlaşılmaktadır. Ayrıca ve/sci oranı $(3,2)$ bakımından daha önce verilen örneklerden farklılık göstermektedir. Bunun dışında Kelkit Vadisi'nden verilen örneklerde olduğu gibi sırt kıllarda görülen çentiklenme kılın yarısından itibaren başlamaktadır. Bazı örneklerde $h_{2}$ kıllarının uçta belirgin şekilde çentikli yapıda (Şekil 24), bazı örneklerde ise Kelkit Vadisi'nden toplanan örneklerde olduğu gibi $h_{2}$ kıllarının uçta hafif çentikli yapıda olduğu görünmektedir (Şekil 23). Türkiye örnekleri, $h_{2}$ kıllarının çentikli yapıda olması bakımından tip örneğinden ve Hollanda örneğinden farklılık göstermektedir. Hollanda örneği az da olsa çentikli yapıda olduğu için Türkiye örnekleri ile benzerdir. Hollanda örneğinde ise çentiklenme kaideden başlayıp zor ayırt edilebilmekte ve bu kıl kamçı şeklinde uzanmaktadır (Şekil 22). 


\section{Teşekkür}

Bu çalışmanın materyalini, Türkiye Bilimsel ve Teknolojik Araştırma Kurumu (TÜB TAK) tarafından desteklenen $113 Z 094$ numaralı projeden elde edilen örnekler ile ilk sıradaki yazarın 2014 Eylül ayında Erasmus + Programı kapsamında Amsterdam Üniversitesi'ne (Hollanda) gerçekleştirdiği ziyaret sırasında topladığı akar örnekleri oluşturmaktadır. Desteklerinden ötürü TÜB TAK’a, Avrupa Birliği Eğitim ve Gençlik Programları Merkezi Başkanlığı'na (Ulusal Ajans) ve Erzincan Üniversitesi ile Amsterdam Üniversitesi'nin Uluslararası lişkiler Koordinatörlüğü'ne teşekkür ederiz.

\section{Yararlanılan Kaynaklar}

Doğan, S., S. Dilkaraoğlu, H. Aksoy, M. Aykut \& Q.-H. Fan, 2014. New occurrence of the hygrobiotic mite family Homocaligidae (Acari, Raphignathoidea) in Turkey: Homocaligus crassipus Fan. Systematic \& Applied Acarology, 19: 447-461.

Doğan, S., M. Bingül, S. Dilkaraoğlu \& Q.-H. Fan, 2015a. Description of a new species of the genus Stigmaeus Koch (Acari: Stigmaeidae) from Turkey, with a list of described species in the world. International Journal of Acarology, 41: 290-299.

Doğan, S., S. Dilkaraoğlu, Q.-H. Fan, S. Sevsay, O. Erman, S. Adil, 2015b. Description a species of the genus Cheylostigmaeus Willmann (Acari: Stigmaeidae) from Ekşisu Marsh, Turkey. Systematic \& Applied Acarology, 20: 797-808.

Dönel, G. \& S. Doğan, 2011. The stigmaeid mites (Acari: Stigmaeidae) of Kelkit Valley (Turkey). Zootaxa, 2942:1-56.

Fakhari, N., M. Khanjani, H. Rahmani \& M. Khanjani, 2015. Stigmaeus jalili sp. nov. (Acari: Stigmaeidae) from Zanjan Province, Iran and description male of $S$. haddadi. Biologia, 70: 782-787.

Fan, Q.-H. \& Z.-Q. Zhang, 2005. Raphignathoidea (Acari: Prostigmata, Fauna of New Zealand, 52: 1-400.

Grandjean, F., 1944. Observations sur les acariens la famille de Stigmaeidae. Archives des Sciences physiques etnaturelles, 26: 103-131.

Kethley, J., 1990. "Acarina: Prostigmata (Actinedida), 667-756". In: Soil Biology Guide, (Ed. D.L. Dindal). John Wiley and Sons, New York, 667 pp.

Khanjani, M., F. Amini \& M. Khanjani, 2015. A new species of the genus Stigmaeus Koch (Acari: Stigmaeidae) from Kurdistan Province, Iran and description of Prosigmaeus khanjani Bagheri and Ghorbani. Acarologia, 5: 49-60.

Kuznetsov, N.N., 1977. A contribution to the fauna of mites of the family Stigmaeidae (Acariformes) in the CentralChernozem Zone. Zoologischeskii Zhurnal, 56: 953-956.

Summers, F.M., 1962. The genus Stigmaeus (Acarina: Stigmaeidae). Hilgardia, 33: 491-537

Uluçay, ., 2015a. Stigmaeus ceylani, a new species of the genus Stigmaeus Koch (Acari: Stigmaeidae) from Turkey. Turkish Journal of Entomology. 39: 35-46.

Uluçay, ., 2015b. Two species of stigmaeid mites from Turkey: Eryngiopus coheni Vacante \& Gerson, 1987 and Stigmaeus berwariensis n. sp.(Acari: Stigmaeidae). International Journal of Acarology, 41: 214-219.

Yeşilayer, A. \& S. Çobanoğlu, 2013. stanbul (Türkiye) park ve süs bitkilerinde tespit edilen Raphignathoid akarları (Acari: Prostigmata: Raphignathoidea). Turkish Journal of Entomology, 37: 93-103.

Zhang, Z.-Q., Q.-H. Fan, V. Pesic, H. Smit, A.V. Bochkov, A.A. Khaustov, A. Baker, A. Wohltmann, T.-H. Wen, J.W. Amrine, P. Beron, J.-Z. Lin, G. Gabrys \& R. Husband, 2011. Order Trombidiformes Reuter, 1909. In: Zhang, Z.-Q. (Ed.), Animal biodiversity: an outline of higher-level classification and survey of taxonomic richness. Zootaxa, 3148: 129-138. 